Bol. Acad. peru. leng. 64. 2018 (205-219)

\title{
EUFEMISMOS Y DISFEMISMOS EN EL DISCURSO POLÍTICO DE LA PRENSA ESCRITA DE LIMA
}

\author{
Úrsula Yvonne Velezmoro Contreras
}

$\begin{array}{ll}\text { Fecha de recepción: } & 02 / 08 / 2018 \\ \text { Fecha de aceptación: } & 31 / 10 / 2018\end{array}$

En la actualidad, los medios de comunicación impresos se caracterizan por emplear eufemismos y disfemismos en sus publicaciones, especialmente en el discurso político. Las diferencias en el uso de estas expresiones dependen de diversas razones, como la línea editorial del periódico, la coyuntura política, el repertorio lingüístico, la intención comunicativa, lo políticamente correcto, la sensibilidad del redactor y del lector, el prestigio social, el tipo de nota (nota informativa, sección de datos, crónica, reportaje de investigación), el público al que va dirigido y la especialización del diario (político, de espectáculos, de actualidad, etc.).

Al no existir estudios lingüísticos sobre el tema en nuestro país, esta investigación busca describir su contexto de uso y saber cuáles son los procesos lingüísticos que intervienen en la formación de los eufemismos y disfemismos en el discurso político de la prensa escrita de Lima. Para ello, se han considerado las teorías y metodologías empleadas en El eufemismo

https://doi.org/10.46744/bapl.201802.011 
y el disfemismo/Procesos de manipulación del tabú en el lenguaje literario inglés (2007), de Eliecer Crespo, obra que «confirma una tendencia generalizada de los estudios en torno a la interdicción lingüística: las referencias a la lengua literaria como fuente de análisis eufemístico y disfémico resultan insuficientes»; el Diccionario de eufemismos (2000), de José Lechado, que "puede utilizarse de forma similar a un glosario de sinónimos e incluye casi todo tipo de eufemismo»; y La interdicción lingüística/Mecanismos del enfemismo y disfemismo (1986), de Miguel Casas, investigación que se «basa en la esfera central de la prostitución, una de las parcelas léxicas de mayor relieve sociológico, particularmente en las designaciones peninsulares de «prostituta» en el español moderno, siglos XIX (especialmente a partir de la segunda mitad) y XX».

Esta investigación tiene como objetivo analizar los eufemismos y disfemismos empleados en el discurso político de la prensa escrita de Lima, para lo cual se ha realizado un estudio de los diarios El Comercio, Perú21, Publimetro Perú y Trome, de las ediciones impresas del 1 de octubre de 2015 al 30 de junio de 2016, desde el punto de vista lexicográfico, morfosintáctico, semántico y sociolingüístico. Es un análisis descriptivo que sigue el método inductivo, pues parte de un corpus constituido por palabras y expresiones de la prensa escrita de Lima y busca establecer generalizaciones pertinentes. Por otro lado, el trabajo correlaciona las expresiones lingüísticas con algunos aspectos socioculturales, a fin de establecer los significados correspondientes.

Después de estas consideraciones, se sostiene que la formación de eufemismos y disfemismos en el discurso político en la prensa escrita de Lima (DPPL) se realiza mediante procesos lingüísticos, presenta características particulares y tiene interpretaciones sociolingüísticas particulares a la lengua profesional del periodista de la sección de Política.

\section{Los eufemismos del DPPL}

De acuerdo con el Diccionario de la lengua española (DLE), el eufemismo es la «manifestación suave o decorosa de ideas cuya recta y franca expresión sería dura o malsonante». 
Para Miguel Casas Gómez (1986: 64-65), «el juego eufemístico consta de dos fases bien diferenciadas: una primera en la que tiene lugar una sustitución del término interdicto por el sustituto eufemístico, y una segunda en la que se produce una conversión, el sustituto se va haciendo opaco hasta asumir la carga peyorativa del sustituido que, análogamente, correrá la misma suerte que su predecesor».

Como bien señalan estos investigadores, en los diarios previamente seleccionados, se puede observar que el eufemismo tiene una vida útil corta; por ello, su proceso de producción es muy frecuente y rápido en este tipo de discurso.

De acuerdo con José Manuel Lechado (2000), las causas para la creación de eufemismos son las siguientes:

- Malsonancia. Se centra en insultos y otras expresiones consideradas de mala educación (camaleón).

- Motivaciones de tipo político-económico. Son formas diplomáticas y protocolarias (clase media trabajadora).

- Motivaciones sociales. Depende de situaciones muy diversas, como la compasión, la presunción o cursilería (diferencias ideológicas).

- Motivaciones culturales. Están marcados por la tradición y los usos de la costumbre que en muchos casos han caído en desuso o incluso han adquirido valores negativos alejados del eufemismo original (populórum).

- Necesidades de prestigio profesional. Es característico de ciertas profesiones; a menudo, se trata de extranjerismos (outsider).

- Ignorancia. Se refiere al empleo de extranjerismos innecesarios en los tecnicismos (spot publicitario, bullying político).

- Significados trasladados. Se dan con frecuencia en el mundo político (centroizquierda moderno).

- Marcas comerciales. Son fruto de las campañas publicitarias (ley pulpin). 
https://doi.org/10.46744/bapl.201802.011

\subsection{Análisis semántico de los eufemismos del DPPL}

Como indica Lechado (2000), los eufemismos en el discurso político de la prensa escrita de Lima (DPPL) pueden formarse de diferentes maneras, recurriendo a diversos procedimientos lingüísticos y figuras retóricas:

- Sinonimia. Emplea palabras con significado idéntico o semejante, para reforzar un concepto (bombre pro familia).

- Circunlocuciones y perífrasis. Consiste en utilizar más palabras de las necesarias para expresar una idea o concepto (empleado fantasma, caminar derecho).

- Sinécdoque. Es la designación de una cosa con el nombre de otra (mapochino).

- Antonomasia. Alude a alguien mencionando una cualidad muy característica suya en lugar de su nombre propio (el líder de la chakana).

- Metáfora. Es un recurso propio de la literatura que también se utiliza en el DPPL (ley seca, candidato pitufo, partido vientre de alquiler).

- Infantilismo. Crea eufemismos cursis (Toledo es el patito feo de la política).

- Antífrasis. Consiste en el uso de eufemismos paradójicos, dada la inversión del significado (La candidata presidencial reiteró que su padre cometió el grave error político de permitir que cometieran delitos sobre su gobierno).

- Lítote. Se basa en la negación para expresar la intención del hablante (arma no letal).

- Negación. Coloca un prefijo negativo para que se invierta el significado de una palabra determinada (despenalizar, impresentable, inseguridad ciudadana).

- Extranjerismos. Por lo general, se recurre al empleo de extranjerismos innecesarios, con el único afán de crear un eufemismos de tipo social, político y económico. El idioma más influyente es el inglés (lobby, men, service), seguido del francés 
https://doi.org/10.46744/bapl.201802.011

(impasse), del italiano (vendetta), del japonés (harakiri) y del noruego (troll).

\subsection{Variantes del eufemismo}

En el discurso político de la prensa escrita de Lima (DPPL) se han encontrado algunas variantes de este fenómeno lingüístico:

- El término eufemístico. Se han hallado términos eufemísticos nominales (psicosocial), verbales (despolitizar), adjetivales (candidato histórico) y adverbiales (tendenciosamente).

- La locución eufemística. Como señala Crespo, la sustitución eufemística se realiza mediante las locuciones nominales (los de arriba), locuciones verbales (marcar distancia, parar la olla), locuciones adjetivales (bajo la lupa), locuciones preposicionales (en campaña) y locuciones adverbiales (tampoco tampoco).

- El enunciado eufemístico. Existen expresiones y enunciados con valor eufemístico (roba, pero hace obras; no es plagio, es copia).

\section{Los disfemismos del DPPL}

De acuerdo con el $D L E$, el disfemismo es el «modo de decir que consiste en nombrar una realidad con una expresión peyorativa o con intención de rebajarla de categoría, en oposición al eufemismo».

Según Crespo, «las definiciones más acertadas del disfemismo las proponen Casas (1986: 85-86) y Allan y Burridge (1991: 26). Para estos autores, el disfemismo se basa en la sustitución del tabú, pero no se vincula ni al lenguaje exclusivamente malsonante, ni jocoso, ni vulgar. Para Casas Gómez, el disfemismo "busca [...] no ya la mitigación o atenuación, sino su efecto contravalente, la motivación o reforzamiento del signo interdicto". Por su parte, Allan y Burridge incluyen en su definición una alusión al contexto discursivo y al efecto del disfemismo en el receptor, con lo que señalan el carácter pragmático del fenómeno: el disfemismo es una expresión 
https://doi.org/10.46744/bapl.201802.011

con connotaciones que son ofensivas ya sea al objeto en mención, al público o a ambos, y es sustituida por una expresión neutral o eufemística por esa razón».

Como señalan los investigadores, el disfemismo no tiene que ser un insulto o una palabra soez, simplemente puede ser una expresión malintencionada que genere una reacción negativa y que ponga en duda la trayectoria, la honradez o el prestigio social de una persona o de un partido político.

\subsection{Análisis semántico de los disfemismos del DPPL}

De acuerdo con Crespo, los procedimientos para crear disfemismos son los siguientes:

- Insulto. Constituye la variante más evidente de la ofensa verbal (la hija del dictador, perro de chacra y la trilogía del mal).

- Disfemismos interjectivos. Cumplen una función catártica, liberan tensiones y constituyen un medio de dar salida a frustraciones y enfados (missnistra).

- Formas directas. Se emiten ciertos términos o enunciados de forma directa, sin recurrir a las estrategias de tipo eufemístico. La brusquedad de las formas imperativas, de las preguntas directas o la referencia explícita a ciertas realidades incómodas, sin la presencia de términos o fórmulas atenuadoras, pueden ofender al receptor o introducir un elemento de tensión en la conversación (candidato de los empresarios).

- Designaciones jocosas. La intención de amplificar el tabú propia del disfemismo se puede conseguir también mediante el recurso del humor, que se aprecia tanto en designaciones jocosas como en chistes (el «Darth Vader» del fujimorismo).

\subsection{Variantes del disfemismo}

En el discurso político de la prensa escrita de Lima (DPPL) se han encontrado algunas variantes de este fenómeno lingüístico: 
https://doi.org/10.46744/bapl.201802.011

- El término disfemístico. Una palabra es capaz de ofender al receptor o causar tensión en el acto comunicativo. Morfológicamente, estos son sustantivos (chuponeador), verbos (facturar, lloriquear) y adjetivos (trucho, chamuscado).

- La locución disfemística. El hablante utiliza las locuciones nominales (fujimorista duro, caviar conversa), locuciones verbales (bajar el dedo, echar barro con ventilador), locuciones adjetivales (doble cara, borrachita de poder) y locuciones preposicionales (por las patas de los caballos).

- El enunciado disfemístico. Existen expresiones y enunciados con valor disfemístico (otorongo no come otorongo, la plata llega sola, plata como cancha, primer damo, mi campaña será sin millones ni ladrones).

\section{Análisis lexicográfico del DPPL}

De acuerdo con el Diccionario de lingüística, de Theodor Lewandowski (1986: 208), la lexicografía es la «doctrina de la realización de diccionarios, el trabajo de diccionarios como aplicación de los conocimientos lexicológicos y la satisfacción de las exigencias o necesidades teóricas y prácticas; la representación del vocabulario de una lengua (natural), un dialecto, una especialidad».

Los periodistas de Política reconocen que tienen una lengua profesional $^{1}$ que va cambiando de acuerdo con la coyuntura política y que se refleja en el lenguaje; sin embargo, también son conscientes de que esta es diferente a la lengua de los políticos. En el ámbito periodístico, la situación, la coyuntura y -en algunos casos- el escándalo se apropian del lenguaje. No solo en los diarios chicha, sino en todos se recoge información y se reconstruye la realidad en el discurso político de la prensa escrita de Lima. Un ejemplo de ello es que ahora todo escándalo de corrupción se

1 Como afirma Luis Hernán Ramírez, en Estructura y funcionamiento del lenguaje (1996:146), «las lenguas profesionales son especializaciones de la lengua estándar que corresponden a diferentes ramas de la actividad humana. Cada profesional llega a poseer su nomenclatura propia con términos y voces y hechos específicos de la profesión cuyos significados resultan confusos y desconocidos para las personas ajenas a la profesión». 
https://doi.org/10.46744/bapl.201802.011

denomina faenón. Es ahí donde se refleja cómo la coyuntura política se apodera del lenguaje.

Como señala Luis Hernán Ramírez (1996: 136), «entre la lengua común y las especiales no existe un límite claro y preciso. Cualquiera que asome a nuevos campos de la actividad humana participará de las lenguas que corresponden a esos campos en una proporción que depende de sus dotes y habilidades y de la intensidad de su intervención. Entre la lengua común y las especiales existe un continuo intercambio de términos. [...] Las lenguas especiales son de dos tipos: abiertas (lenguas profesionales y lenguas de artesanía) y cerradas (jergas y lenguas de juventud)».

Esta investigación recoge los eufemismos y disfemismos que se emplean en el discurso político de la prensa escrita de Lima (DPPL), entradas que han sido recogidas de las notas de la sección de Política, de las columnas Cortitas y Pepitas, de las ediciones impresas de los diarios El Comercio, Perú21, Publimetro Perú y Trome, del 1 de octubre de 2015 al 30 de junio de 2016. Solo se han considerado las palabras más significativas y recurrentes de los diarios seleccionados. De estas palabras, ciento setenta y nueve (179) son eufemismos y ciento nueve (109), disfemismos.

Para la elaboración de los artículos lexicográficos, se contrastó cada una de ellas con el Diccionario de la lengua española (DLE), el Diccionario de americanismos $(D A)$ y el Diccionario de peruanismos $(D P)$.

Se emplean las marcas de las voces técnicas procedentes de la especialidad del periodismo político (Per. Pol.); diatópica (Lim.); de valoración social (vulgar) y la marca pragmática (desp., por despectivo). Los extranjerismos crudos son voces que se registran en letra cursiva; mientras que los adaptados ajustan su escritura al uso del español y a las normas de acentuación del mismo. Las marcas registradas se hacen constar en el paréntesis etimológico.

Las entradas están dispuestas de acuerdo con el orden latino internacional. El contorno, en caso de ser necesario, se ubica antes de 
https://doi.org/10.46744/bapl.201802.011

la definición seguido de dos puntos. En cuanto a las formas complejas, estas se organizan en función al primer elemento compositivo: sustantivo. Además de registrar las entradas constituidas por una sola palabra, el DPPL recoge una serie de palabras que, combinadas de una determinada manera, expresan conceptos no interpretables mediante la simple adición de los significados de sus componentes. Para economizar espacio, en los artículos se emplea la virgulilla $(\sim)$ como sustituto del lema.

\subsection{Estructura de los artículos lexicográficos del DPPL}

Al inicio de cada artículo, aparece un lema escrito en negrita, tamaño de letra número 12 , que presenta la unidad léxica buscada. Se indica si la entrada es una enmienda al $D L E$ con el signo (E); una enmienda del $D A$, (Ea); una enmienda del $D P$, (Ep); una nueva acepción, (NA); una nueva acepción de forma compleja, (NAFC), y una nueva forma compleja, (NFC) después de la entrada. Para señalar que la entrada no está en el $D L E$, el $D A$ y el $D P$ se colocará el signo de más $(+)$ antes de la entrada.

En los casos en que se necesite, se precisará la información etimológica encerrada en un paréntesis. Después, se presenta la marca gramatical para las formas simples (m., f., m. y f.) y para las formas complejas se emplea (loc. nom., loc. adj., loc. v., loc. adv., loc. prep.), seguida de la marca de extranjerismo (extr.), eufemismo (euf.) o disfemismo (disf.), la marca sociolingüística (col. y p. u.).

Todas las definiciones son lexicográficas. Aparece la acepción o acepciones correspondientes al lema, separadas por una doble pleca cuando hay más de una $(\|)$. Para indicar una cadena sinonímica, después de la definición se emplea el signo de un rombo $(\star)$. Cuando una entrada deba escribirse con mayúscula inicial, se indicará (ORT. Se escribe con mayúscula inicial). Al final del artículo lexicográfico, se puede remitir a una definición a través del (*). Como en el $D L E$, no se presentan ejemplos de uso. 
histórico. [...] || (NA) adj. Per. Pol. Perú. euf. Que tiene mucha experiencia y sabiduría. dinosaurio.

mermelero. [...]\| (NAp) adj. Per. Pol. Perú. disf. Que recibe sobornos U. t. c. s.

\section{Interpretación lingüística del DPPL}

De acuerdo con el análisis, se puede manifestar que, en el discurso político de la prensa escrita de Lima (DPPL), la construcción de las palabras y las locuciones se produce mediante procesos morfosintácticos en contextos extralingüísticos que surgen en el entorno de los periodistas de política.

La categoría gramatical que más predomina es el nombre (faenón), seguido del verbo (politizar), el adjetivo (picón) y el adverbio (tendenciosamente).

Con respecto al nivel sintáctico, los datos muestran un predominio de locuciones nominales (piedrita en el zapato), seguido de las locuciones verbales (poner paños fríos), las locuciones preposicionales (a boca de urna), las locuciones adjetivales (bajo la lupa) y las locuciones adverbiales (tampoco tampoco). En las locuciones verbales, se impone la combinación de verbos más nombres (marcar distancia, sacar chispas).

En el nivel semántico, es más recurrente la producción de eufemismos (desubicado), seguida de la de disfemismos (mermelero) y de los extranjerismos (vendetta). Según el corpus, se evidencia una predilección por el uso de los extranjerismos crudos (blooper) en comparación con los adaptados (kit).

En cuanto a los disfemismos, las formas de designaciones jocosas tienen mayor presencia en los artículos de opinión o en la sección de datos (candidato pinocho). 
https://doi.org/10.46744/bapl.201802.011

\section{Interpretación sociocultural del DPPL}

Por lo general, el profesional de esta área es periodista de carrera, varón y, en algunos casos, el menos experimentado de la redacción. Realiza su trabajo visitando el Congreso de la República, el Palacio de Gobierno, el Poder Judicial y el Ministerio Público; no obstante, según del contexto y la coyuntura, también se debe incluir a la Defensoría del Pueblo, los partidos políticos, el Jurado Nacional de Elecciones, el Registro Nacional de Identidad y Estado Civil y la Oficina Nacional de Procesos Electorales, este último sobre todo en época de elecciones — como es el caso de este análisis-.

Las personas con quienes interactúan para conseguir la información son políticos, funcionarios públicos y servidores públicos. La duración del acto comunicativo, generalmente, es muy corta y con interferencias — salvo en las entrevistas previamente pactadas-.

Según los informantes, el periodismo político era considerado la cúspide profesional, ya que para ejercerlo se debía pasar por todas las áreas de la redacción (Locales, Internacionales, Espectáculos, Deportes, Economía); hoy, debido a la crisis internacional de los medios de comunicación, se contrata a recién egresados. No obstante, en algunas redacciones, hay periodistas de la sección de Política con experiencia y fuentes que les brindan las herramientas necesarias para publicar primicias.

El estilo de la redacción de los contenidos va a variar según el tipo de medio; es decir, si es un diario tradicional, conservador o chicha; si va dirigido a jóvenes o adultos; así como si es un diario eminentemente político, de espectáculos o de actualidad. También dependerá del tipo de nota porque no se analizará lo mismo. De acuerdo con los periodistas, cuando son notas informativas, el lector quiere conocer qué sucedió y debe citar lo que el entrevistado dijo, por una cuestión de responsabilidad y para que no parezca una nota interpretativa. Sin embargo, si es una crónica o reportaje de investigación, se puede escribir una nota con más análisis; porque ahí no se necesita contar la historia, sino lo que está detrás 
https://doi.org/10.46744/bapl.201802.011

de esta: los detalles y las causas del conflicto. En el caso de la sección de datos (Cortitas, Pepitas), se emplea un lenguaje sarcástico mediante el empleo de disfemismos. Asimismo, dependerá del contexto, del repertorio lingüístico, de la intención comunicativa, de lo políticamente correcto, de la sensibilidad del redactor y del lector, y del prestigio social.

\section{Conclusiones}

- La producción de eufemismos es más rica que la de disfemismos. Sin embargo, los eufemismos -como señalan los investigadores - tienen una vida muy corta y se convierten rápidamente en disfemismos. Se ha podido observar que en el discurso político de la prensa escrita de Lima (DPPL) este fenómeno se acelera.

- El proceso de producción de eufemismos más recurrente en el DPPL es el de la metáfora; mientras que en el de los disfemismos - en todos los tipos de diarios que han sido motivo de esta investigación - son las designaciones jocosas, los cuales aparecen en mayor número en las secciones de datos.

- Entre los procesos lingüísticos que intervienen en la formación de los eufemismos y disfemismos en el DPPL, los procesos morfológicos más recurrentes son el de composición sintagmática y el de derivación por sufijación. Dentro de los procesos sintácticos que sufren estos términos, las frases verbales y las nominales son las que se producen con mayor frecuencia en el DPPL, seguida de las frases preposiciones.

- Existe una predilección por el empleo de extranjerismos crudos en comparación con los adaptados en el DPPL. Los más frecuentes son los que provienen del inglés. En el caso de los extranjerismos adaptados, estos presentan problemas de acentuación y escritura españolas.

- En el caso de las expresiones dichas por los excandidatos presidenciales, aunque son reproducciones, estas reflejan la intención disfemística de cada uno de ellos.

- El discurso político en la prensa escrita de Lima es una reconstrucción de la realidad y de un repertorio lingüístico especí- 
https://doi.org/10.46744/bapl.201802.011

fico; sin embargo, los redactores de esta área intentan plasmar lo mejor posible cada una de las declaraciones de estos personajes en sus notas, lo cual se evidencia en una redacción con muchas citas textuales.

- Los redactores de esta especialidad reconocen que existe una lengua profesional que es diferente de la lengua de los políticos. Tanto los redactores como los editores, de acuerdo con el medio de comunicación y el público al que va dirigido, buscan acercar la realidad a los lectores con un lenguaje sencillo y claro. 
https://doi.org/10.46744/bapl.201802.011

\section{BIBLIOGRAFÍA}

ASALE. (2010). Diccionario de americanismos. Perú: Santillana.

ACADEMIA PERUANA DE LA LENGUA. (2016). DiPerú/Diccionario deperuanismos. Lima, Perú: Academia Peruana de la Lengua.

CASAS, M. (1986). La interdicción lingüística/Mecanismos del eufemismo y disfemismo. Cádiz, España: Universidad de Cádiz.

CHAMIZO, P., \& SÁNCHEZ, F. (2000). Lo que nunca se aprendió en clasel Eufemismos y disfemismos en el lenguaje erótico inglés. Albolote, Granada, España: Comares.

CRESPO, E. (2007). El eufemismo y el disfemismo/Procesos de manipulación del tabú en el lenguaje literario inglés. Alicante, España: Universidad de Alicante.

HAENSCH, G. (1982). La lexicografía. De la lingüística teórica a la práctica. España: Gredos.

LECHADO, J. (2000). Diccionario de eufemismos/El primer Diccionario de Eufemismos del español actual. Madrid, España: Verbum.

LEWANDOWSKI, T. (1986). Diccionarios de lingü̈stica. Madrid: Cátedra Lingüística.

MIRANDA, L. (2000). Semántica estructural (Lexemática). Perú: Juan Brito/Editor.

PORTO DAPENA, J. (1980). Elementos de lexicografía / El diccionario de construcción y régimen de R.J. Cuervo. Colombia: Publicaciones del Instituto Caro y Cuervo LV.

REAL ACADEMIA ESPAÑOLA. (2014). Diccionario de la lengua española, Madrid: Espasa Calpe. 
https://doi.org/10.46744/bapl.201802.011

. (2009). Nueva gramática de la lengua española. Morfología / Sintaxis I / Sintaxis II. España: Espasa Libros, S. L. U., tomos I y II.

. (2010). Ortografía de la lengua española. España: Espasa Libros, S. L. U.

RAMÍREZ, L. (1996). Estructura y funcionamiento del lenguaje. Perú. M \& B Editores Impresores.

ROTAETXE, K. (1988). Sociolingüística. España: Síntesis. 